\title{
Facial and Hand Scars Appearance after Autologous Nanofat Grafting in Patients with Post Burn Scars
}

${ }^{1}$ Muhammad Arfan Ishaque, ${ }^{1}$ Muhammad Ali Rafique Mirza, ${ }^{2}$ Maria Sharif,

${ }^{3}$ Ahmed Wahab Arshad

${ }^{1}$ Department of Plastic surgery, Shaikh Zayed Medical Complex, Lahore

${ }^{2}$ Department of Public Health and Community Medicine, Shaikh Zayed Medical Complex, Lahore

${ }^{3}$ Department of Plastic Surgery, Children Hospital Faisalabad Hospital, Lahore

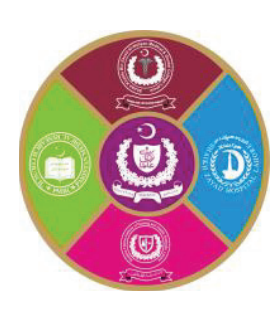

\begin{abstract}
Introduction: Management of unsightly post-burn scars has changed tremendously in current era of cosmetic awareness. 5-12\% of all worldwide injuries are burn injuries and approximately 11 million patients need hospital care. Multiple treatment methods for scar improvement including fat grafting are under investigation. Nano fat Grafting is newer modality of fat grafting for improving scar quality. Aims \& Objectives: The aim of this study was to assess the outcome of facial and hand scars appearance after autologous Nanofat grafting in patients with post burn scars. Place and duration of study: The study was performed in Plastic Surgery Department of Shaikh Zayed hospital, Lahore Pakistan from October 2018 to September 2019. Material \& Methods: 30 patients with post-burn scars of face and hands were included; age range was 18 to 43 years. Skin type 2 to 4 (Fitzpatrick skin type). Patients with skin graft, hypertrophic scars, contractures, or keloids were excluded. Scars were assessed by the patients and observer on a scale "POSAS" (Patient and Observer Scar Assessment Scale), the observer was a plastic surgeon. Scar was assessed before surgery using the POSAS scar scale. Fat was taken from the abdomen using $3 \mathrm{~mm}$ cannulas with side holes of $1-2 \mathrm{~mm}$ under tumescent conditions and transferred to $10 \mathrm{cc}$ syringes with luer-lock. Nano fat obtained after emulsification by passing 30 times from one syringe to another through luer-lock. The follow up was on $7^{\text {th }}$ day, at 3 months and at 6 months. Results: The mean POSAS score of observer decreased significantly from admission $35.8 \pm 4.0$, at 3 months $31.3 \pm 3.8$ and 6 months to $27.5 \pm 3.0, \mathrm{p}$ value $<0.05$. The mean POSAS score of patients also significantly decreased, $\mathrm{p}$ value $<0.05$ over the same time period from admission at $42.4 \pm 5.2$, to 3 month $37.3 \pm 4.0$ and 6 month to $32.2 \pm 3.2$. Conclusion: Nano fat grafting results in improvement in scar appearance and is an effective approach towards the management post burn scar of face and hands.
\end{abstract}

Key words: Autologous, Nano fat Grafting, Post Burn Scars

\section{INTRODUCTION}

$\mathrm{T}_{\mathrm{he}}$ management of burn has changed tremendously during the past few years. In an era where a lot of emphasis is placed on cosmesis and has a direct socioeconomic impact, unsightly post burn scars specially on the face and hands causes psycho-socioeconomic distress to the patients as well as their families. Burns account for $5-12 \%$ of all injuries worldwide with about 11 million patients requiring medical care. ${ }^{1,2}$

Post burn scaring on the face and hands presents major stigma as it becomes adherent to the underlying structures due to the absence of sliding layer resulting in decreased range of movement and inflexibility of skin. It also leads to hyper pigmentation, hypertrophic scarring and keloid as well as contractures formation. The plastic surgeons are constantly striving to improve the current techniques that would improve the appearance of these scars.

Different treatment modalities are available for treatment of post burn scarring which include pressure garments, topically applied silicone, intralesional steroids, scar excision, scar excision with skin grafting, tissue repositioning, contracture release and $\mathrm{Z}$ plasty, tissue expansion, synthetic fillers and laser therapy. ${ }^{3,4}$

Autologous fat grafting was initially reported in the early twentieth century. Ever since, the advancements are being made to this technique. In recent years, autologous fat grafting has become increasingly popular for many indications such as in 
posttraumatic deformities, age process, post radiotherapy breast reconstruction. ${ }^{5}$

Autologous fat grafting is new choice to improve the appearance of scare especially where medical and surgical options seem to be less effective. A study was conducted to evaluate the improvement of scar appearance by using POSAS scale after fat grafting. Participants were divided into two parts one treated with fat graft and other with saline solution. The results showed that there is significant overall change in mean POSAS score. Observer Pre and Post procedure Values, POSAS Parameters, and $\mathrm{P}$ Value from mean score 5.9 to 4.5 with $\mathrm{P}$ - value $<0.05$ and Patient Pre and Post procedure Values, POSAS Parameters Overall mean score from 5.3 to 2.1 P-value $<0.05$ consider significant. ${ }^{6}$

Regarding the complication of Nano fat grafting, adipose drive stem cells present in Nano fat do not cause the keloid formation rather it inhibits bioactivity of keloid fibroblast related activity. ${ }^{7}$

Due to multiple benefits of Nano fat grafting shown in various studies, is increasingly in vogue. Nano fat grafting is a new modality in improving scar quality, it does not act as a filler as there are no viable adipocytes present after emulsification but stem cells are present which are a great help in skin rejuvenation and in improving skin quality. ${ }^{8}$

RCT was published in 2016 to evaluate the safety of adipose drive stem cells in athymic mouse for tumor formation ability and sterility testing. The results showed that adipose drive stem cell is safe for stem cell therapy. ${ }^{9}$

But due to its unpredictable survival rates there is a need for development of new techniques to improve graft viability. ${ }^{10,11}$

Keeping in mind the challenges faced in the surgical management of post burn scar and their disappointing and variable results. We aimed to assess the effect of Nano fat grafting in post burn scars of face and hand.

\section{MATERIAL AND METHODS}

This prospective study was held at Plastic and Reconstructive Surgery Department Shaikh Zayed Hospital, Lahore from October 2018 to September 2019. Patients with post-burn scars on face and hands was treated with Nano fat grafting. The Inclusion criteria were post burn scars of face and hands; Fitzpatrick skin type 2 to 4; age above 18 years (Both genders); mature scars $(\geq 1$ year) and indoor workers. Grafted skin, hypertrophic scars, keloids and contractures were excluded.

Patients were admitted from Plastic Surgery Out Patient Department, Shaikh Zayed Hospital, Lahore using non-probability purposive sampling technique. The scar quality was assessed before surgery using the POSAS scar scale. POSAS is Patient and Observer Scar Assessment Scale in which patient and observer (a plastic surgeon) assesses the scar quality of same area before and after treatment. The POSAS score for the surgeon was given by an experienced plastic surgeon oblivious to the patient score. Tumescent solution was injected using Klein's formula (lidocaine $800 \mathrm{mg} / \mathrm{l}$ and adrenaline $1: 1000,000)$ at the donor site. After waiting for 10 minutes for the solution to take effect, fat was harvested using $3 \mathrm{~mm}$ cannulas with side holes of $1-2 \mathrm{~mm}$ under tumescent conditions. Fat was strained and washed 3 times with normal saline to remove any blood and tumescent solution. Fat was transferred to $10 \mathrm{cc}$ syringes connected with a Leur-lock and the fat transferred from one syringe to the other through the Luer-lock at least 30 times to emulsify it. Thereafter, the fat was transferred into $1 \mathrm{cc}$ syringes fitted with 27 Gauge needles for injection into the scar. Patients were injected with Nano-fat only in the subdermal plane at the recipient site. ${ }^{6}$

The follow up was on $7^{\text {th }}$ day, at 3 months and then at 6 months when the patient and same surgeon will again score the scar using the POSAS scale.

\section{Statistical analysis:}

Data was entered and analyzed by using SPSS 21. The quantitative variables Age, Area of Scar, thickness of scar, amount of Nano fat used for both groups was presented as Mean \pm S.D.

Comparison between time and groups was made by using repeated measures of ANOVA. P-value $<0.05$ considered significant.

\section{RESULTS}

30 patients were included in the study. The mean age of patients was $27.2 \pm 5.8$ years with an age range between 18 and 27 years. There were 12 $(40.0 \%)$ male and $18(60.0 \%)$ female cases. Majority of patients $25(83.1 \%)$ developed scars due to $3^{\text {rd }}$ degree burns while $4(13.3 \%)$ with $2^{\text {nd }}$ degree and only one patient $(3.3 \%)$ had $1^{\text {st }}$ degree burns. The location of scars was $93.3 \%$ on face and $6.7 \%$ was on hands. The mean width of scar was $5.2 \pm 2.1$ $\mathrm{cm}^{2}$ and mean length was $6.1 \pm 2.1$. The mean volume of Nano fat injected was $9.5 \pm 4.4 \mathrm{ml}$. 


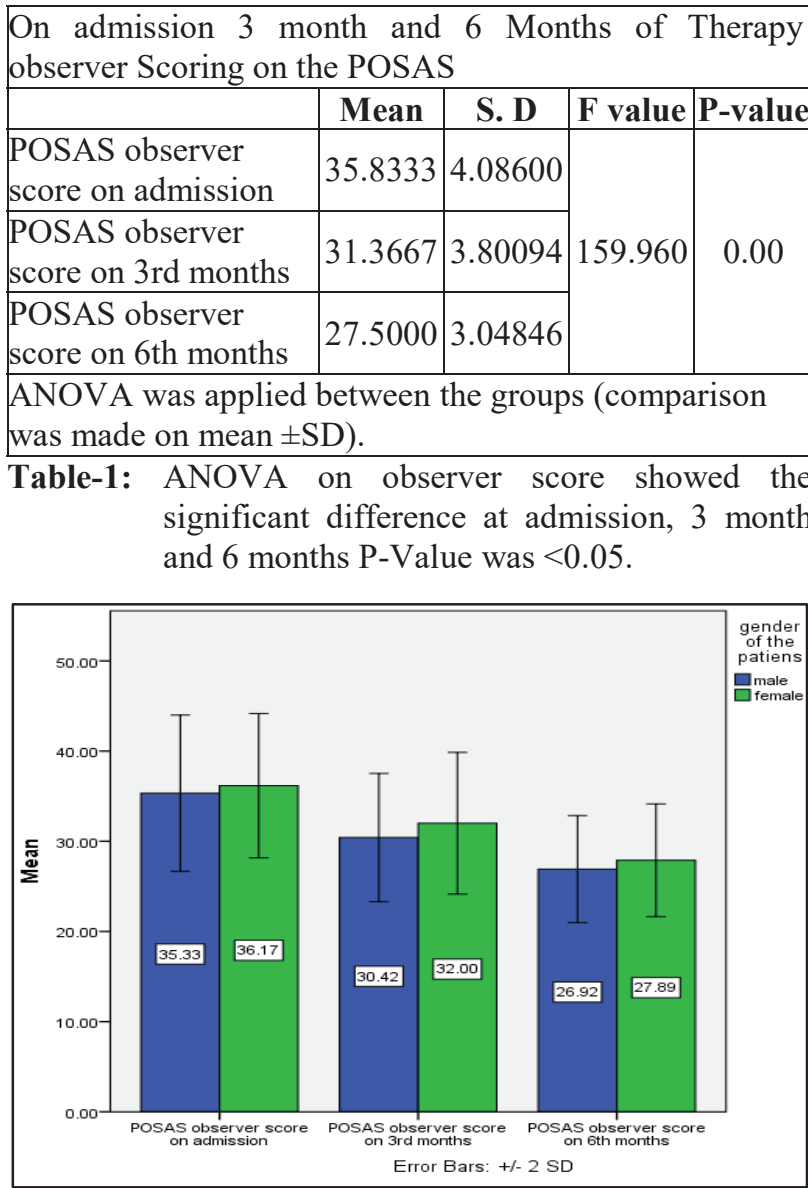

On admission 3 month and 6 Months of Therapy patients Scoring on the POSAS

\begin{tabular}{|l|c|c|c|c|}
\hline & Mean & S. D & F value & P-value \\
\hline $\begin{array}{l}\text { POSAS patient score } \\
\text { on admission }\end{array}$ & 42.4000 & 5.24306 & & \\
\cline { 1 - 2 } $\begin{array}{l}\text { POSAS patient score } \\
\text { on 3rd month }\end{array}$ & 37.3000 & 4.00990 & 113.4 & 0.00 \\
\cline { 1 - 2 } $\begin{array}{l}\text { POSAS patient score } \\
\text { on 6th months }\end{array}$ & 32.2333 & 3.25559 & & \\
\hline
\end{tabular}

ANOVA was applied between the groups (comparison was made on mean $\pm \mathrm{SD}$ ).

Table-2: ANOVA was applied on patients score which was also significant at admission, 3 month and 6 months P-Value was $<0.05$.

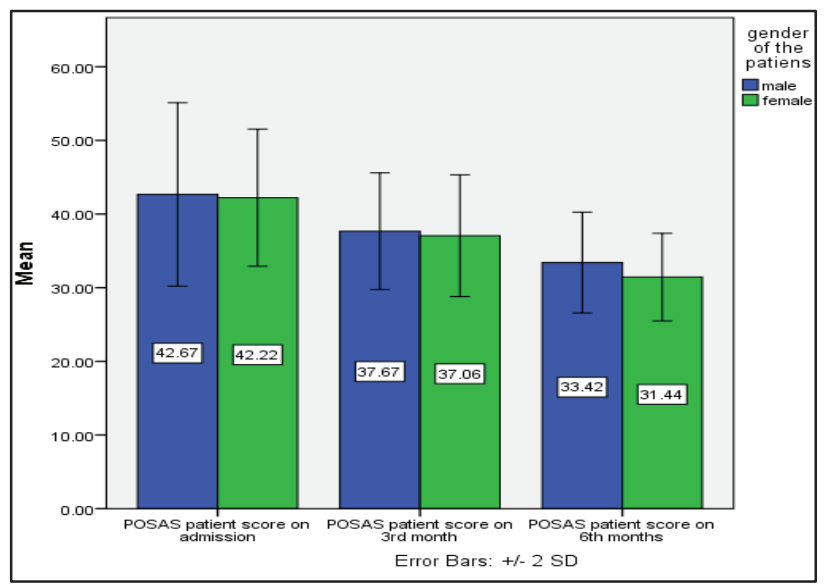

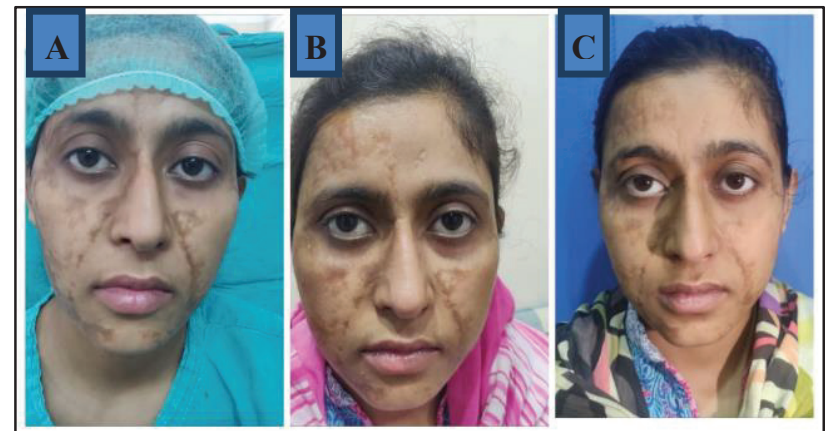

Fig-1: A 23 year old female with post burn ( $3^{\text {rd }}$ degree $)$ scars on face. A is the preoperative photo and $\mathrm{B}$ is the 3-month post-operative photos and $\mathrm{C}$ is after 6 months of duration.

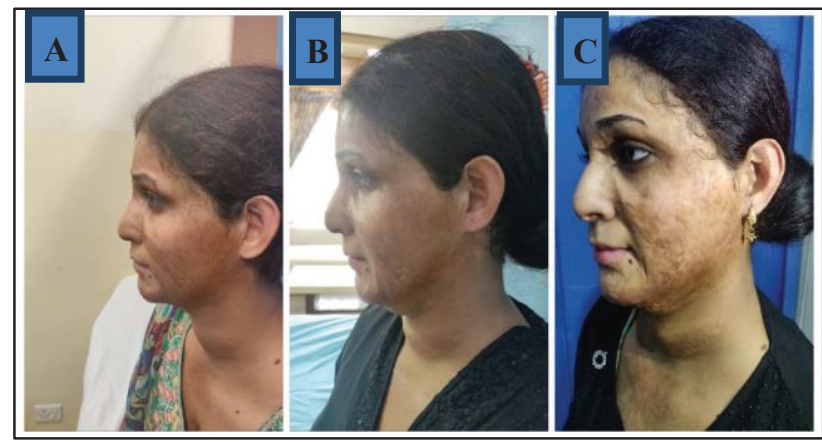

Fig-2: A 28-year-old female with post burn ( $3^{\text {rd }}$ degree $)$ scars on face. A is the preoperative photo and $\mathrm{B}$ is the 3-month post-operative photos and $\mathrm{C}$ is after 6 months of duration.

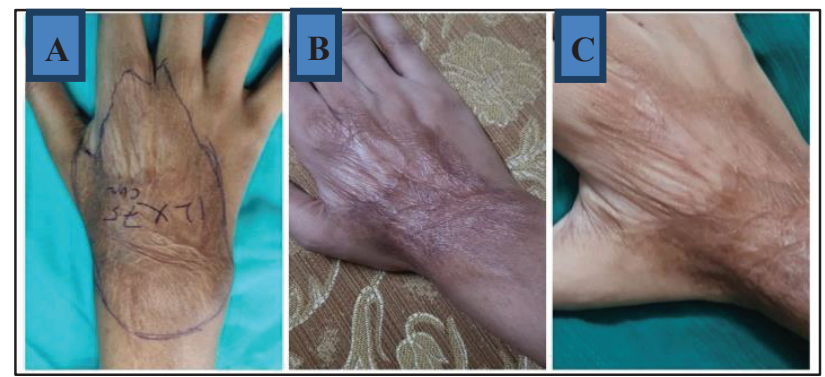

Fig-3: A 21-year-old male with post burn ( $3^{\text {rd }}$ degree $)$ scars on hand. A is the preoperative photo and B is the 3-month post-operative photos and $\mathrm{C}$ is after 6 months of duration.

\section{DISCUSSION}

Healing of burn wounds is necessary to understand the acute management of burn wounds, their prevention, avoidance of post burn scars, contractures and their treatment. ${ }^{5,8}$ Different therapeutic modalities are available for treatment of post burn scarring which include pressure garments, topically applied silicone, intra-lesional steroids, scar excision, scar excision with skin grafting, tissue repositioning, contracture release and $\mathrm{Z}$ plasty, tissue expansion, synthetic fillers and Laser therapy. ${ }^{3,4}$ 
Nano fat is a simple method which is cost effective, need less time, requiring no special skills and arrangement. The study was conducted to investigate the effects of Nano on post burn facial scar rejuvenation. In our study Nano fat grafting proved to be viable and effective entrant in the field of scar management. Appearance of Post Burn Scars was statistically different from admission at $3^{\text {rd }}$ month and $6^{\text {th }}$ month in POSAS scale following sessions of Nano fat injection. In our study it seems to be a preferred choice in post burn scar management. Appearance of Scars was significantly improved in each session. Adipose stem cell (ASC) present in Nano fat rejuvenate the overlying skin. ${ }^{12}$

Keloids and hypertrophic scars were excluded from the study because they have different pathology that requires regression but not rejuvenation. Results show that the mean observer score changed from admission to 3 months 6 month follow up. A similar prospective study was conducted at Plastic and Reconstructive Surgery Department of Mayo Hospital Lahore with a sample size of 42 patients. More than one-year old facial scars were treated with Nano fat injection and score was calculated through POSAS. The results were comparable to our study with decrease in mean POSAS score. The mean observer score changed from $30.46 \pm 3.99$ to $22.0 \pm 4.2$ in duration of 6 month and patient score changed from $38.4 \pm 5.1$ to $20.67 \pm 2.30 .{ }^{13} \mathrm{In}$ another study conducted in 2018 to determine that Adipose-derived stem cells (ADSC) combined with PRP can increase the survival of transferred fat tissue. When the rats were injected with fat and PRP GRAFT survival increased. ${ }^{14}$

In our study the comparison on POSAS was done before starting the treatment, at 3 months and 6 months on patient and observer score. The Independent Sample t-test was insignificant at admission with p-value at 0.35 and 0.41 while at $3^{\text {rd }}$ month 0.01 and 0.00 and $6^{\text {th }}$ month the $p$ value was 0.00 and 0.00 on observer and patient score respectively. Another study conducted in China was aimed to evaluate the effect of condensed Nano fat combined with fat grafting in treatment of facial scars from both functional and aesthetic perspectives. The results were similar to our study in the final follow-up examinations, overall POSAS score significantly improved among both patients and observer score. ${ }^{15}$

\section{CONCLUSION}

Nano fat therapy is yet another treatment modality with promising results that can be offered to the unfortunate burn victims with statistically significant improvement in cosmetic post burn scars of face and hands.

\section{REFERENCES}

1. Peck MD. Epidemiology of burns throughout the world. Part I: Distribution and risk factors. Burns. 2011;37(7):1087-100.

2. Rybarczyk MM, Schafer JM, Elm CM, Sarvepalli S, Vaswani PA, Balhara KS, et al. A systematic review of burn injuries in low-and middle-income countries: Epidemiology in the WHO-defined African Region. African Journal of Emergency Medicine. 2017; 7(1):30-7.

3. Tredget EE, Levi B, Donelan MB. Biology and principles of scar management and burn reconstruction. Surgical Clinics. 2014; 94(4): 793-815.

4. Modarressi A. Platlet rich plasma (PRP) improves fat grafting outcomes. World journal of plastic surgery. 2013; 2(1):6.

5. Rigotti G, Marchi A, Galie M, Baroni G, Benati $\mathrm{D}$, Krampera $\mathrm{M}$, et al. Clinical treatment of radiotherapy tissue damage by lipoaspirate transplant: a healing process mediated by adipose-derived adult stem cells. Plastic and reconstructive surgery. 2007; 119(5):1409-22.

6. Klinger M, Caviggioli F, Klinger FM, Giannasi S, Bandi V, Banzatti B, et al. Autologous fat graft in scar treatment. Journal of Craniofacial Surgery. 2013; 24(5):1610-5.

7. Wang X, Ma Y, Gao Z, Yang J. Human adipose-derived stem cells inhibit bioactivity of keloid fibroblasts. Stem cell research \& therapy. 2018; 9(1):40.

8. Tonnard P, Verpaele A, Peeters G, Hamdi M, Cornelissen M, Declercq H. Nanofat grafting: basic research and clinical applications. Plastic and reconstructive surgery.2013;132(4):1017-26

9. Zhou Y, Wang J, Li H, Liang X, Bae J, Huang $X$, et al. Efficacy and safety of cell-assisted lipotransfer: a systematic review and metaanalysis. Plastic and reconstructive surgery. 2016; 137(1):44e-57e.

10. Tolba AM, Nasr M. Initial Experience of Face Augmentation Using Fat Graft-Platlet Rich Plasma Mix. Surgical Science. 2015; 6(11):489.

11. Abuzeni PZ, Alexander RW. Enhancement of autologous fat transplantation with platelet rich plasma. The American Journal of Cosmetic Surgery. 2001; 18(2):59-70.

12. Musumeci G, Lo Furno D, Loreto C, Giuffrida $\mathrm{R}$, Caggia S, Leonardi R, et al. Mesenchymal stem cells from adipose tissue which have been differentiated into chondrocytes in three- 
dimensional culture express lubricin. Experimental biology and medicine. 2011; 236(11):1333-41

13. Aziz F, Choudhery MS. Unfiltered Nanofat Injections Rejuvenate Postburn Scars of Face. 2018.

14. Seyhan N, Alhan D, Ural AU, Unal A, Avunduk MC, Savaci N. The Effect of Combined Use of Platelet Rich Plasma and Adipose Derived Stem Cells on Fat Graft Survival. Plastic and Reconstructive Surgery. 2012; 130(5S-1):71.

15. Gu Z, Li Y, Li H. Use of condensed nanofat combined with fat grafts to treat atrophic scars. JAMA facial plastic surgery.2018;20(2):128-35.

\section{The Authors:}

Dr. Muhmmad Arfan ishaque

P.G. Trainee,

Department of Plastic Surgery,

Shaikh Zayed Medical Complex, Lahore.
Dr. Muhmmad Ali Rafique Mirza

Head, Department of Plastic Surgery,

Shaikh Zayed Medical Complex, Lahore.

Maria Sharif

Biostatistician,

Department of Public Health \& Community Medicine Shaikh Zayed Medical Complex, Lahore

Dr. Ahmed Wahab Arshad

Senior Registrar,

Department of Plastic Surgery,

Children Hospital, Faisalabad

\section{Corresponding Author:}

Dr. Muhmmad Arfan ishaque

P.G. Trainee,

Department of Plastic Surgery,

Shaikh Zayed Medical Complex, Lahore.

E-mail: dr_arfan_rana@hotmail.com 